\title{
Higher Education Instructors' Use, Perceptions, and Practices of Mobile Learning in Morocco
}

Youness Zidoun $\mathrm{PhD}^{1 *}$, Nabil Zary MD, $\mathrm{PhD}^{1}$

1. Institute for Excellence in Health Professions Education (ieHPE), Mohammed Bin Rashid University of Medicine and Health Sciences, Dubai, United Arab Emirates

*Corresponding author:

Youness Zidoun, PhD

Institute for Excellence in Health Professions Education (ieHPE)

Mohammed Bin Rashid University of Medicine and Health Sciences (MBRU)

Dubai, United Arab Emirates

Email. Youness.Zidoun@mbru.ac.ae 


\begin{abstract}
Background: In an age where information is generally accessible, most of the interest these days has focused on how accessible and convenient technology can be. So small and personal, mobile devices can transform our perception of learning by combining both mobility and convenience. Mobile learning is part of the digital learning landscape alongside e-learning and serious games. However, knowledge about effective design of mobile learning experiences remains of interest with a focus on appropriate design models and the embodiments that can be implemented to achieve the intended educational outcomes. Exploring the instructor's perspective on mobile learning is essential. Therefore, the aim of this study was to investigate the Moroccan instructors' perception and practice of mobile learning to inform the development of an ecologically valid mobile learning integration model.
\end{abstract}

Methods: Higher education Instructors $(n=41)$ were recruited to the study. The Moroccan instructors' perception and their experiences regarding their adoption of mobile learning were collected using an online survey. The analysis focused on their mobile use, perceived IT competency, and opinions on mobile learning.

Results: We described most of the instructors' considerations regarding integrating mobile technologies into their teaching activities. We found that most of the mobile learning activities defined by the respondents corresponded to relatively advanced use of mobile devices. More promising, instructors have found innovative ways to use the educational potential of mobile devices. However, the prospect of mobile devices was still to challenge. No or poor Wi-Fi connection, number of devices or limited access, sometimes fees or applications incompatibility were identified as reasons and obstacles to mobile learning usage.

Conclusion: Mobile learning is mostly perceived positively among Moroccan instructors allowing many applications and usage to enhance teaching and learning. In this study, a better understanding of aspects and factors influencing the integration of mobile learning in the Moroccan educational context is exposed, helping further the development of an ecologically valid mobile learning integration model. Future work on mobile learning should consider the highly paced evolution of mobile technologies, emphasizing the flexibility of integration frameworks to support instructors and learners.

Keywords: Mobile learning, Integration framework, Design-based research 


\section{INTRODUCTION}

The development of mobile devices makes m-learning particularly interesting. Born in the early 2000s, this term brings together several innovative pedagogical and technical aspects that are part of the continuity of e-learning principles. The fact that mobile learning brings together several fields of expertise is not without leading to several issues concerning its integration into educational programs. Traditionally, the design of mobile platforms has relied on the skills of mobile developers whose knowledge enables them to design practical mobile applications for users. But with mobile learning, the design phase involves more than simple mobile development skills. Indeed, for example, to design a platform allowing the realization of practical work, it will also be necessary to involve the instructors responsible for the training. Many researchers stated that mobile learning could give place to new designs and teaching methods, helping learners stay creative in the learning process [1] [2]. However, empirical results show that instructors do not effectively integrate technology in general into their teaching approach [3]. To enable these instructors to realize mobile learning platforms, it is necessary to facilitate their integration.

This study aims to complete the design cycles of the theoretical mobile learning integration model [12]. This third design cycle aimed to uncover the missing factors and aspects that had not emerged during the first and second design cycles. An online survey was deemed adequate because it allows information to be quickly collected and a large and varied sample to be reached [15]. The objective was therefore to collect information and examples from a sample of Moroccan instructors regarding their use of mobile learning in their own words and to compare the aspects emerging from their description with those of the previous literature and design cycles.

\section{Theoretical underpinning}

As Park pointed out in 2011, a theoretical framework can guide effective instructional design and evaluation of mobile learning implementations [4]. Therefore, a mobile learning framework and guidelines can bridge the gap between theory and practice and enable sustainable and effective pedagogical integration of mobile technologies in learning contexts. Moreover, the framework and guidelines can also provide a theoretical basis for mobile learning [5].

In her description of mobile learning, Koole defines it as a process resulting from the convergence of mobile technologies, human learning capabilities, and social interactions. The FRAME model (Framework for Rational Analysis of Mobile Education) stresses the technical characteristics of mobile devices, social aspects, and personal aspects of learning. This model combines several objectives, mainly guiding the development of mobile devices and mobile learning supports. It also aims at the design of teaching and learning strategies related to mobile learning.

In the FRAME model, three aspects, the device, the learner, and the social aspects intersect. The device aspect refers to mobile devices' physical, technical, and functional characteristics, such as input and output functionality, storage capacities, and processor computing speed. These characteristics can significantly impact users' physical and psychological comfort levels because the device provides the interface between the learner and his learning task, hence the significant impact on usability. On the other hand, the learning aspect considers an individual's cognitive abilities, memory, prior knowledge, emotions, and possible motivations. In addition, these aspects can significantly influence information retrieval processes by providing access to content in multiple formats and highlighting contexts and uses of information. Lastly, the social element includes the processes of interaction and social cooperation, such as the exchange of information, the acquisition of knowledge, and the maintenance of cultural practices. These intersections, representing the overlap of the three aspects, contain characteristics belonging to both others, as illustrated in the Figure below. Thus, the intersection of device usability has elements shared by both device and learner, including characteristics that may affect the device's usability and the user's feeling of psychological comfort and satisfaction. In contrast, the intersection of social technologies describes how mobile devices enable communication and collaboration between individuals and systems. The interaction and learning intersections consider the impact of this latter on human learning [6]. 


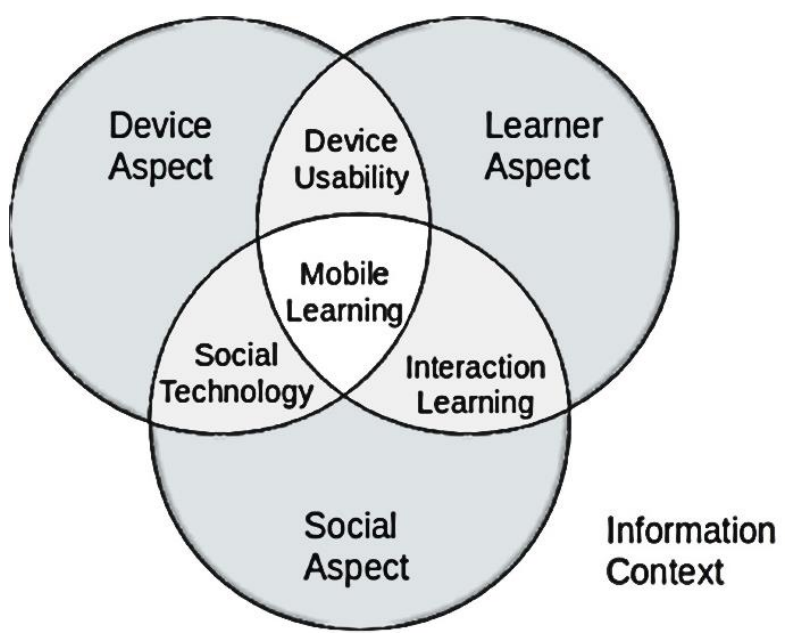

Figure 1. The FRAME framework (REF?)

On the other hand, Kearney et al., in 2012, approached mobile learning from a more pedagogical perspective. They introduced a framework highlighting three essential characteristics of mobile learning: authenticity, collaboration, and personalization, as shown in figure 2. These functionalities are also embedded in the unique spatiotemporal contexts of mobile learning [7].

This model specifies the critical characteristics of mobile learning; it also facilitates and supports the design of mobile learning activities. The very heart of the framework is the space-time junction, which these researchers say profoundly impacts mobile learning experiences. This junction also maintains a close relationship with the essential functionalities of mobile learning, such as personalization, authenticity, and collaboration. Each of the central functions has two other underlying closely related ones.

The authenticity feature, for example, highlights opportunities for contextualized, participatory, and situated learning. Mobile learning activities potentially involve a high degree of authenticity, as learners participate in rich and contextual tasks involving actual practices. In addition, the collaboration emphasizes the conversational and connected aspects of mobile learning. In mobile learning activities, learners can enjoy a high level of collaboration by forging very rich and privileged bonds with other people and the resources conveyed by a mobile device. Finally, the personalization function has a significant impact on the ownership of learning, its arrangement, and the autonomy associated with that learning. This means that learners have control over where, how, and when they learn and can enjoy complete autonomy over their learning content.

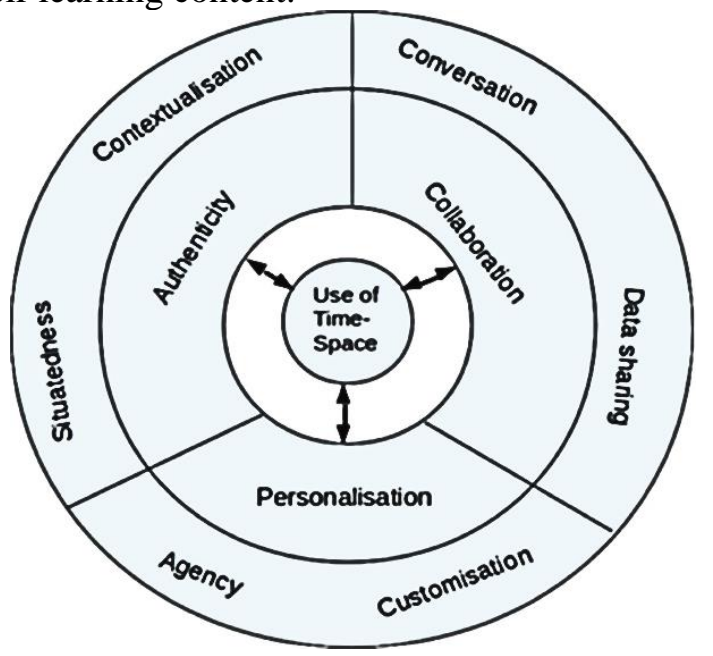

Figure 2. The characteristics of mobile learning, according to Kearney et al. 2012

The learning aspect and the social aspect can be considered as similar between the two models mentioned above. However, unlike Koole's model, Kearney's stems from personalization. This aspect 
includes concerns such as learner choice, representation, self-regulation, and personalization. In other words, the personalization function involves a learner and factors associated with him, which is also found in the learning aspect of Koole's framework. The social aspect is also transcribed in the model of Kearney and al. equally to that of Koole's. This part called collaboration essentially includes the same processes of social interaction and cooperation.

Context, time, and space are at the heart of the Kearney et al. model. Context is particularly emphasized in aspects of authenticity, where learning is projected into the real world and the community. This is also found in Koole's model, which considers that mobile learning experiences exist in an information context. Our previous work [mon article1] indicates that mobile technologies have a unique ability to support learning anywhere and anytime and to extend the learning environment to authentic contexts. Therefore, based on these elements, context, time, and space should be considered central aspects of any mobile learning framework.

Although the device or technology aspects are not directly stated in the framework of Kearney et al., it offers a variety of personalized activities and rich possibilities for connections with other learners and instructors as well as with several resources. In addition, mobile devices are an essential tool for learning on the go. Thus, it is also an aspect that must be recognized and taken into consideration.

\section{METHODS}

The design-based research approach is more used nowadays in innovations and interventions related to educational technologies [8]. In other words, a design-based research approach involves the joint work of researchers and teachers to plan, carry out, analyze, and publish tangible changes in teaching and learning [9]. Design-based research aims to develop interventions (programs, teaching and learning strategies, teaching materials, education systems, etc.) to address complex problems. Therefore, this research approach incorporates cycles of analysis, design, evaluation, and review [10]. These research cycles are dynamic and incorporate many exploratory, constructive, and empirical research methods and strategies and many design techniques [11]. As part of the main goal, which is to design and develop a framework for integrating mobile learning to support its implementation in an educational context, an iterative process of reflection and revision was applied on the primary model considering multiple previous studies [12] [13] [14].

The online survey was compiled using Google's Forms tool (Appendix I). The study participants were recruited via email and WhatsApp groups, and upon acceptance to participate, a link to the survey was shared.

Usually, the specific design task or specific reflected problem determines the collection and analysis of data. Therefore, an online survey was deemed appropriate as it could reach a diverse sample of Moroccan instructors who have previously used mobile devices as part of their teaching practices. All the participants were primarily assistant professors. They were also of different ages and had different levels of ICT skills. They addressed issues related to ICT and the use of mobile devices in the Moroccan educational context. The survey consisted of eight multiple-choice and four open questions. Table 2 presents the survey themes

The topics covered in the survey:

- Personal information

- Use of mobile devices

- Agility and competence of instructors

- Mobile learning activities

- Perspectives 
Table 2. The topics covered in the survey

Data analysis for the open questions was performed using our developed mobile learning theory integration framework, which was revised in the second design cycle. However, when categorizing the use of mobile devices by instructors, the frameworks introduced by Puentedura, Mishra and Koehler, Koole, Kearney were also exploited. In addition, the development of inductive categories was used when categorizing open responses. Data analysis for the open questions was performed using our developed mobile learning theory integration framework (REF?).

\section{RESULTS}

\section{Participant's characteristics}

The participants targeted were all instructors in Moroccan higher education. The respondents' gender distribution was $65 \%$ were female and $35 \%$ male. In addition, $92 \%$ of the participants were between 30 and 49 years old. Without national statistics, the representativeness of the respondents is still to be attested. All respondents had more than one year of experience in higher education. Only a few had more than five years of experience. Thus, the information provided by the respondents indicates that, overall, the survey reached a diverse sample of Moroccan instructors who used mobile devices as part of their teaching practices. The survey, therefore, gave an explicit picture of the current situation of the use of mobile devices in the Moroccan educational context.

\section{Use of mobile devices}

The frequency with which survey respondents used mobile devices as part of their teaching practices, as well as the reasons why they started using a mobile device, were assessed using two questions: How often do you use a mobile device in your teaching practices and What motivated you to use mobile devices in your teaching practices?

Most of the respondents (87\%) used mobile devices daily or weekly, as shown in Table 3

\begin{tabular}{|l|l|l|}
\hline Use of mobile devices & \\
\hline How often do you use a mobile device in your & Daily & $47 \%$ \\
\cline { 2 - 3 } teaching practices? $(\mathbf{n}=\mathbf{4 6})$ & Weekly & $40 \%$ \\
\cline { 2 - 3 } & Monthly & $13 \%$ \\
\hline & Never & $0 \%$
\end{tabular}

Table 3. Use of mobile devices

It is nevertheless evident that the survey was carried out by teachers who had already used mobile devices as part of their teaching practices, none of the respondents having agreed with the following statement: I have never used mobile devices as part of my teaching practices. Only six respondents reported using less frequently (Monthly) mobile devices. Overall, the survey found that the reasons for integrating mobile devices can be split into two primary motivations. First, instructors' interest and their goal of improving or developing their teaching practices, and second, the pressure to progress (e.g., institution bought tablets, students already have access to devices, instructors need to teach skills they will need in the future). Table 4 groups together some of the comments from the survey (quotes were selected randomly). 


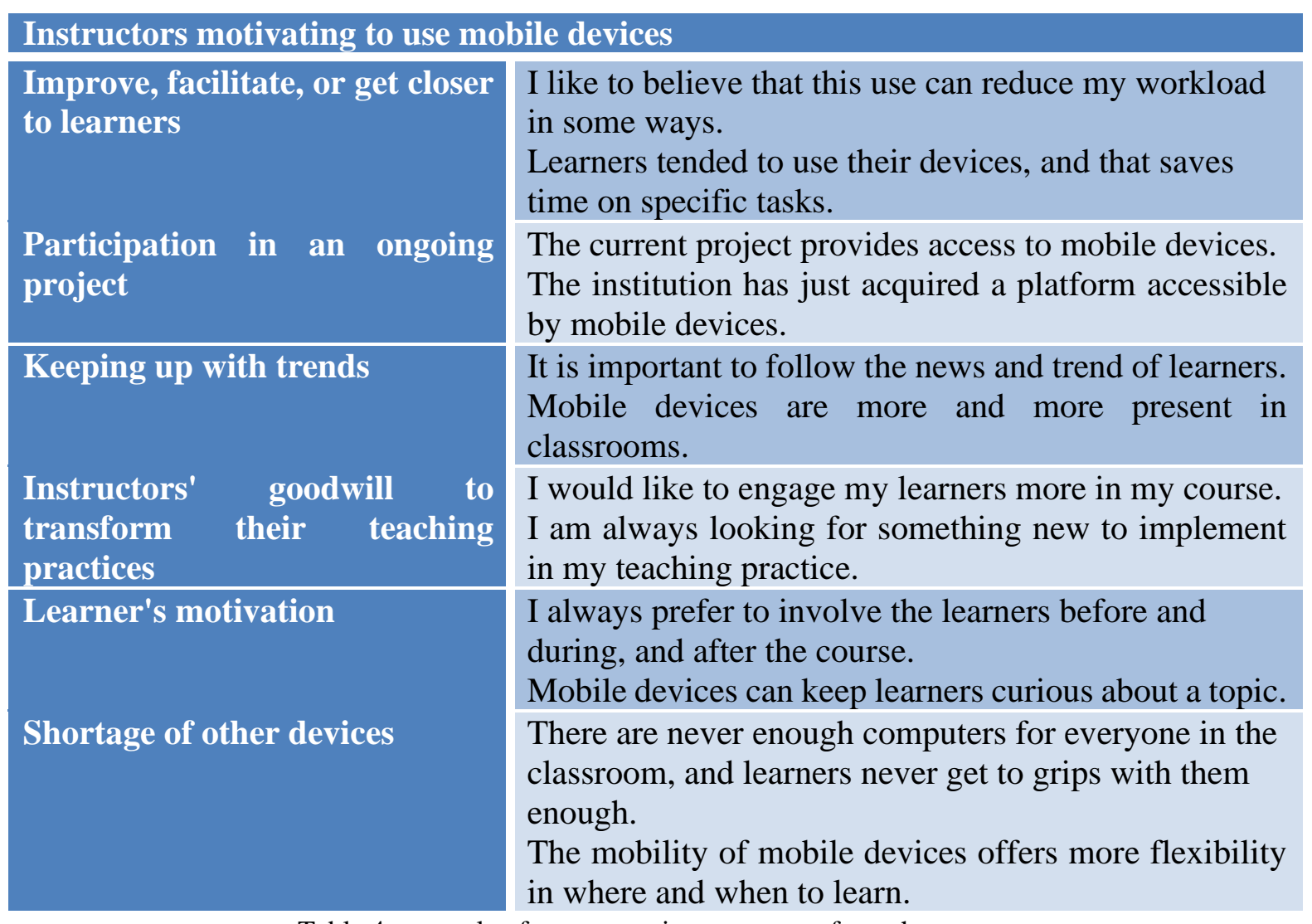

Table 4. example of representative comments from the survey

\section{Agility and competence of instructors}

Instructors' opinions on their own skills were questioned using two questions: Do you think you have enough ICT skills? Do you think that the integration of a mobile device is easy in the taught curriculum?

Almost all respondents (87\%) answered having sufficient skills to integrate mobile devices into teaching and learning practices. However, $37 \%$ of all respondents said that integrating a mobile device into the classroom was difficult, which can be perceived as positive. The reasons that supported or challenged the integration of mobile devices were almost similar but at the same time different. The obstacles mentioned were mainly instructors' skills, ICT integration models and strategies, learning theories, or curriculum. Some of those interviewed pointed out that they did not know how to integrate mobile devices into their teaching practices. Other common arguments were raised, such as the poor quality of the establishment's network.

According to survey respondents, instructors' interest and willingness to train and experiment were cited as essential factors in successfully integrating mobile devices. Another critical factor was the user-friendliness of the application. Mobile devices were considered easy to use. In addition, the motivation of learners to use mobile devices, the support of their peers, and sufficient training were deemed necessary. One respondent also argued that mobile devices were an essential part of their course flow. 


\section{Mobile learning activities}

While describing mobile learning activities by survey participants, 43 among them described their activity, some generally and others briefly. In most cases, mobile devices were used when creating content. The survey results showed that it was common to use mobile devices for improvement. This includes searching for information via the Internet, taking notes, and substituting mobile devices for books or documents. Other widespread ways were the use of mobile devices for performing exercise activities and feedback, such as using multiple choice quizzes/quizzes to present the check or raise awareness of pre-learning requirements, get learner responses and provide feedback. Mobile devices were also used to support forum discussions.

It should be noted that there are surprisingly several cases in which learning has been extended outside the classroom, given that mobile technology can expand the learning environment significantly in the classroom. Table 5 collates some of the comments from the survey on the nature of mobile learning activity (quotes were selected randomly).

\begin{tabular}{|c|c|}
\hline \multicolumn{2}{|c|}{ Categories of mobile learning activity } \\
\hline Content creation & $\begin{array}{l}\text { I use mobile devices in my classroom with learners to initiate } \\
\text { discussion debates to complement comprehension activities. } \\
\text { We identify the educational videos that could feed into our next } \\
\text { science exhibition topics in class with my learners. }\end{array}$ \\
\hline Improved learning & $\begin{array}{l}\text { I ask learners to search for texts online on their mobile devices to } \\
\text { practice reading/listening. } \\
\text { We use an application that allows grouping the work done during } \\
\text { the course }\end{array}$ \\
\hline $\begin{array}{l}\text { Testing and } \\
\text { assessment activity }\end{array}$ & $\begin{array}{l}\text { I use learners' personal mobile devices to answer the pre-test and } \\
\text { post-test of each simulation session. } \\
\text { The learners vote on a WhatsApp group on the continuous control } \\
\text { answers. }\end{array}$ \\
\hline $\begin{array}{l}\text { Collaboration } \\
\text { discussion }\end{array}$ & $\begin{array}{l}\text { We use a WhatsApp group to discuss clinical cases. } \\
\text { Learners post the mock exam answers to a Facebook group and } \\
\text { discuss the possibilities. }\end{array}$ \\
\hline$\overline{\text { Info }}$ & $\begin{array}{l}\text { We use an app to list and classify photos taken in the field for instant study or } \\
\text { later in the lab. } \\
\text { I work on a virtual patient platform that allows you to play clinical cases. }\end{array}$ \\
\hline
\end{tabular}

Table 5 example of representative comments on the nature of mlearning activity

What was found is that most of the mobile learning activities described by the respondents corresponded to relatively advanced use of mobile devices. What was find promising is that instructors have found innovative ways to use the educational potential of mobile devices. However, the potential of mobile devices was still not fully utilized. In trying to identify the reasons why the full potential of m-learning is not being used, the following reasons have been raised: (1) No or poor Wi-Fi connection, (2) Number of devices or limited access, (3) Sometimes fees or applications incompatibility. 


\section{Instructors' Perspectives}

The survey's last question offered participants the opportunity to freely describe their opinions and views on mobile learning. A total of 41 instructors described their perspectives on mobile learning. Pedagogical paradigms, aspects related to learning content, mobile technologies, learning context were the most frequently mentioned aspects in the participants' comments. Discussions involving educational paradigms emphasized on the importance of tailoring learning practice to the unique characteristics of the mobile environment. The participants insisted on the importance of the method which facilitates the implementation of the different paradigms. One respondent noted: "The educational paradigm to be transcribed via mobile devices must be considered with delicacy. Every theory has a very precise method to facilitate its integration".

The content was often stated as the origin of the reflection, which will guide the integration more through the concepts to be covered. The participants always positioned it at the heart of the pedagogy, considering it as a driving force for the adaptation of other aspects. An example of respondents' responses was: "Each subject, course or educational discipline imposes a certain number of considerations to be respected in order to guarantee effective teaching and learning".

Mobile technologies were also a big part of the participants' considerations. Between the major asset of successful integrations according to respondents and the greatest challenge to overcome, this factor divided participants between skeptical and enthusiastic. Some respondents pointed out that this aspect is the strong point of any successful integration of mobile learning. An answer example was: "Mobile technologies are at the heart of any successful integration of mobile learning, all technical aspects must be aligned and well thought out for such learning to be successful".

As illustrated before in the 5-axis theoretical mobile learning integration model [12], the learning context came in the responses of survey participants from different aspects. Participants inspired to divide the context according to two main aspects. First, factors related to the learning environment. Participants stressed that the learning environment was a big influence on its success. One respondent noted: "Mobile apps that could detect locations, as well as the precise time of learning, were fascinating to use and integrate into teaching practice". The second major aspect of the learning context was the profile of the learners. In a recorded response, one participant pointed out: "Monitoring is possible for each learner via their own mobile device, a way for the teacher to get closer to his learners and to facilitate their learning".

The most general view of mobile learning was rather positive, noting some surmountable challenges that involve several stakeholders. Mobile learning is seen as a new way of looking at teaching practice, innovation, collaboration, and cooperation in learning.

\section{DISCUSSION}

Discussions involving pedagogical paradigms always emphasized the importance of adapting learning practice to the unique characteristics of the mobile environment. Going along with the first proposed framework [12], participants emphasized the importance of the method that 
facilitates implementing the different paradigms. The content was often stated as the origin of the reflection that will further guide the integration through the concepts to be covered and the marriage with the adopted learning theory. The participants always positioned it at the heart of the pedagogy, considering it a driving force for adapting the other aspects. Mobile technologies were a big part of the considerations of survey participants. Between the significant asset of successful integrations according to respondents and the greatest challenge to overcome, this factor divided participants between skeptical and enthusiastic. Some respondents pointed out that this aspect is the strong point of any successful integration of mobile learning. Learning contexts have been distinguished by participants from different angles. The proposed model [12] presents the context according to two main aspects. Factors related to the learning environment and learners' profile. Both can be very impactful towards the success of the whole learning.

The most general view of mobile learning was quite positive. However, noting some challenges according to teachers that involve multiple stakeholders, mobile learning is seen as a new way of looking at teaching practice, innovation, collaboration, and cooperation in learning. In other words, it was made clear that mobile devices are increasingly used in the Moroccan educational context, not as a one-off or occasional activity, but on a weekly and even daily in some cases.

As part of the review cycle of our previously proposed model, the results were similar to those of the second design phase. This study has clarified that in the mobile learning process, the most important aspects are those connected with the learning context, namely: the learner, the technology, and the different interactions between them that constitute the environment. The new aspect highlighted was the design and decisions affecting the learning activity itself, which is one of the essential considerations to add to the model, as shown in the Figure below.

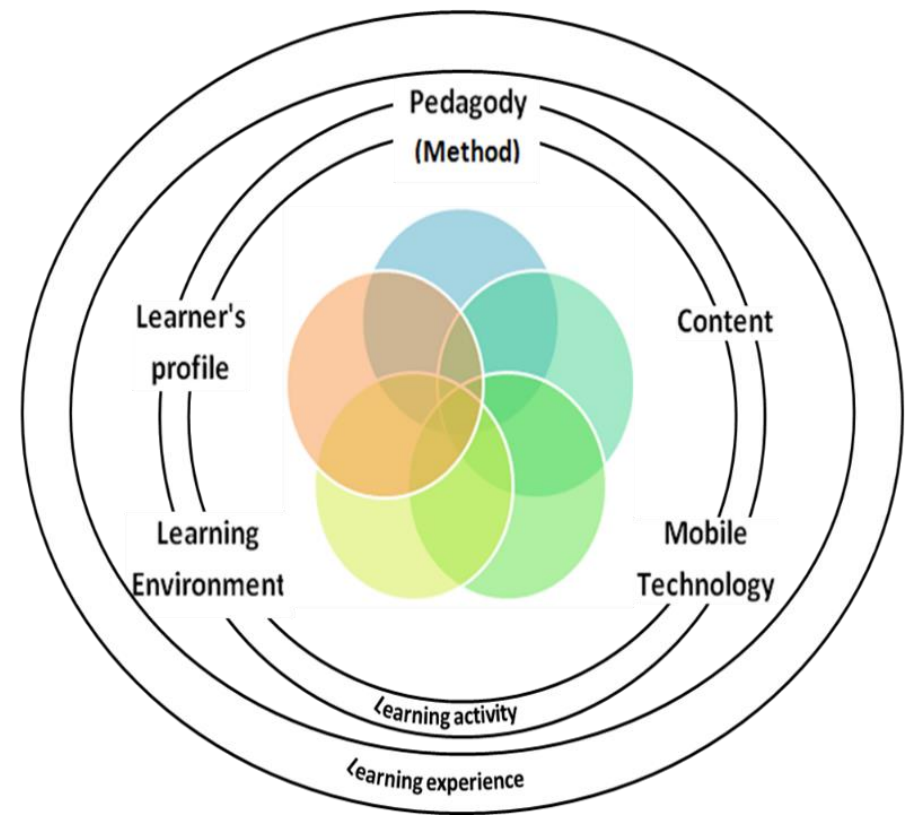

Figure 4. A proposed model of theoretical integration of mobile learning

The design of the learning activity includes pedagogical and contextual considerations, which also consider the needs and preferences of the learner, the usability and intuitiveness of the technology involved, and the design of the user interactions that influence significantly unique and personalized learning experiences. 


\section{CONCLUSION}

This study provided an understanding of mobile learning and the aspects and factors that influence the process of integrating it in an educational context in Morocco. However, it should be noted is that only some of the great potentials of mobile learning have been discovered. Therefore, it is still difficult to predict how mobile technologies in educational settings will develop in the future. Yet, how mobile learning is and will be used will depend primarily on the practices of teachers and instructors. It is also essential to recognize that technology changes rapidly and that next-generation devices may offer new opportunities and thus highlight different aspects to consider in future integrations.

APPENDIX I. The online survey

The topics covered in the online survey:

\begin{tabular}{|l|l|}
\hline 1. Personal information & $\begin{array}{l}\text { Gender [multiple choice:] (male) (female) } \\
\text { Age [multiple choice:] (<30 years) (30-39 years) (40-49 years) } \\
\text { (50-59 years) } \\
\text { Teaching experiences [multiple choice:] (<1 year) (1-5 years) } \\
\text { (5-10 years) (> 10 years) }\end{array}$ \\
\hline 2. Use of mobile devices & $\begin{array}{l}\text { How often do you use a mobile device in your teaching } \\
\text { practices? [multiple choice:] (Daily) (Weekly) (Monthly) } \\
\text { (Never) } \\
\text { Why did you start using mobile devices as part of your } \\
\text { teaching practices? [Open question] }\end{array}$ \\
\hline $\begin{array}{l}\text { 3. Agility and competence } \\
\text { of instructors }\end{array}$ & $\begin{array}{l}\text { Are you ready to use ICT in your teaching activity? [multiple } \\
\text { choice:] (Yes) (No) } \\
\text { Do you think you have sufficient ICT skills? [multiple choice:] } \\
\text { (Yes) (No) } \\
\text { Do you think that the integration of a mobile device is easy in } \\
\text { the taught curricula? [multiple choice:] (Yes) (No) }\end{array}$ \\
\hline $\begin{array}{l}\text { Give some reasons why or why not? [Open question] } \\
\text { Give an example of one of your mobile learning activities } \\
\text { [Open question] }\end{array}$ \\
\hline 4. Mobile learning \\
activities
\end{tabular}




\section{REFERENCES}

[1] Uzunboylu, H. and Ozdamli, F., 2011. Teacher perception for m-learning: scale development and teachers' perceptions. Journal of Computer assisted learning, 27(6), pp.544-556.

[2] Hu, S.K., Lu, M.T. and Tzeng, G.H., 2014. Exploring smart phone improvements based on a hybrid MCDM model. Expert Systems with Applications, 41(9), pp.4401-4413.

[3] Kurt, A., Kuzu, A., Dursun, O., Gullepınar, F., \& Gultekin, M. (2013) FATĐH projesinin pilot uygulama surecinin değerlendirilmesi: oğretmen gorusleri. Journal of Instructional Technologies \& Teacher Education. 2(1), 1 -23.

[4] Park, Y. 2011. A pedagogical framework for mobile learning: Categorizing educational applications of mobile technologies into four types. The International Review of Research in Open and Distance Learning 12 (2).

[5] Viberg, O., \& Grönlund, A. 2012. Mobile Assisted Language Learning: A Literature Review. In M. Specht, J. Multisilta \& M. Sharples (Eds.) mLearn 2012 Mobile and Contextual Learning. Proceedings of the 11th International Conference on Mobile and Contextual Learning 2012, Helsinki, 9-16.

[6] Koole, M. L. (2009). A model for framing mobile learning. In M. Ally (Ed.), Mobile learning: Transforming the delivery of education and training (pp. 25-50). Edmonton, Canada: AU Press.

[7] Kearney, M., Schuck, S., Burden, K., \& Aubusson, P. 2012. Viewing mobile learning from a pedagogical perspective. Research in Learning Technology 20

[8] Anderson, T., \& Shattuck, J. 2012. Design-Based Research: A Decade of Progress in Education Research? Educational Researcher, 41 (1), 16-25.

[9] Stemberger, T., \& Cencic, M. 2014. Design-based research in an educational research context. Sodobna Pedagogika vol. 65 , no. $1,62-89$.

[10] Plomp, T. 2007. Educational Design Research: and intoduction. In T. Plomp and N. Nieveen (Eds.) An Introduction to Educational Design Research. Proceedings of the seminar conducted at the East China Normal University, Sanghai (PR China) November 23-26, 2007. SLO Netherlands institute for Curriculum development, 9-36.

[11] Bannan, B. 2007. The Integrative Learning Design Framework: An Illustrated Example from the Domain of Instructional Technology. In T. Plomp and N. Nieveen (Eds.) An Introduction to Educational Design Research. Proceedings of the seminar conducted at the East China Normal University, Sanghai (PR China) November 23-26, 2007. SLO Netherlands institute for Curriculum development, 53-72.

[12] Zidoun, Y., Dehbi, R., Talea, M. and El Arroum, F.Z., 2019. Designing a Theoretical Integration Framework for Mobile Learning.

[13] Zidoun, Y., Dehbi, R. and Talea, M., 2018. Multi-Criteria Analysis and Advanced Comparative Study between M-learning Development Approaches. International Journal of Interactive Mobile Technologies, 12(3).

[14] Zidoun, Y., Talea, M. and Dehbi, R., 2016. Students' Perception about Mobile Learning in Morocco: Survey Analysis. International Journal of Interactive Mobile Technologies (iJIM), 10(4), pp.80-84.

[15] Sue, V. M., \& Ritter, L. A. 2007. Conducting Online Surveys. Los Angeles: Sage Publications, 2007. eBook Collection (EBSCOhost), EBSCOhost. 